\title{
Esquenazi, Jean-Pierre (2002). L'Écriture de l'actualité: pour une sociologie du discours médiatique. Grenoble: Presses Universitaires de Grenoble.
}

Felisbela Lopes*

Se o subtítulo não reunir força suficiente para impor um determinado contrato de leitura, nas primeiras páginas deste livro, Jean-Pierre Esquenazi introduz-nos no caminho que percorrerão as páginas que temos pela frente: “interessam-nos os produtos dos media que definiremos não como 'textos', mas como 'discursos'. Esta pequena modificação lexical é a expressão de um olhar diferente sobre objectos particulares. Queremos examiná-los mais enquanto sociólogos do que como semiólogos, mais como factos sociais do que como actos de linguagem" (p. 8). Nessa abordagem, este professor da Universidade Lyon 3 e investigador do Centre de Sociologie des Pratiques et des Représentations Culturelles de Grenoble tem já trabalho publicado que lhe permite aventurar-se num percurso que visa tirar das zonas sombrias alguns modos através dos quais os media traduzem o estado do mundo, contribuindo, assim, para nos devolver em palavras e imagens o desenho do universo em que habitamos. Refira-se, por exemplo, Le Pouvoir d'un média: TF1 et son discours (ed. L'Harmattan, Paris, 1996). Na publicação que aqui tratamos, mais do que do papel difusor dos meios de comunicação social, do que se fala é dos media como uma instância que (re)constrói uma realidade social, num permanente processo de interacção entre o que está dentro (do campo mediático) e o que está fora (noutros campos sociais).

Numa obra que questiona a prática discursiva dos media, há referências teóricas imprescindíveis. Esquenazi não falha os principais nomes. De Peter Berger e Thomas Luckman, recupera principalmente a noção de "mundo comum", que lhe permite falar da actualidade como a apresentação de algo que se pensa ser partilhado por muitos actores e que se constitui como "um quadro" de referência para a vida social (p. 27). O autor já nos falara desta capacidade dos media para criarem "quadros de formulação de opiniões" em La Communication de l'information, um livro que publicara em 1997, onde reúne artigos de outros investigadores franceses. Talvez aqui tivesse sido útil ir mais longe na exploração do ensaio A Construção Social da Realidade, a obra de referência de Berger e Luckman que, apesar de não se deter particularmente nos meios de comunicação social, deixa pistas interessantes para pensar a realidade discursiva das instituições mediáticas, ao enfatizar, por exemplo, o facto de o mundo social resultar de uma construção feita através da partilha de significados, assumindo-se a linguagem como uma possibilidade de neutralizar a subjectividade do mundo vivido, na medida em que, através dela, se ultrapassam o "aqui e agora", construindo-se um amplo sistema de representação simbólica em que os respectivos esquemas de classificação possibilitam experiências colectivas de outras realidades. São precisamente esses esquemas que constituem aquilo a que os autores chamam o “acervo social de conhecimentos”. E não é exactamente isso que constitui parte da matéria- -prima da informação mediática? Esquenazi prefere ficar pela alusão, intersectando

* Docente de jornalismo do Curso de Comunicação Social da Universidade do Minho (felisbela@ics.uminho.pt) 
rapidamente este conceito com outro, o de "espaço social", uma noção cara a Pierre Bourdieu, que marca aquilo que é diferente, aquilo que se fragmenta e que fixa barreiras simbólicas.

Integrando o "mundo comum" e prestando atenção às diferentes categorias do "espaço social", os media procuram sempre um compromisso entre ambos, "mesmo se", como se reconhece, "o equilíbrio é difícil de encontrar" (p. 30). Em grande parte, esse trabalho desenvolve-se através da adopção daquilo que Goffman designa como "quadros", ou seja, formas específicas de experiências socialmente organizadas. É essa "postura particular" (p. 34) que define a actividade jornalística que, aliás, merece um capítulo intitulado "As notícias, fundamento da actualidade" (pp. 45-74).

Partindo do postulado de que "a actualidade é o nosso mundo comum tal como é proclamado pelos media" (p. 45), Esquenazi procura iluminar factores que condicionam a noticiabilidade. Nessa tarefa surge-lhe, num primeiro momento, a "lógica editorial", através da qual cada meio de comunicação social constrói uma identidade discursiva e define, consequentemente, o seu lugar no espaço social (p. 47). Outro elemento-chave é o "mundo comum" que o público partilha entre si e que, numa conjuntura concorrencial como o actual, ganha uma importância acrescida. "A corrida às audiências", escreve Esquenazi, "parece levar a privilegiar quadros menos sensíveis às diferentes formas de vida; a emoção é, por exemplo, uma escolha eficaz nesta perspectiva" (p. 48).

Anunciada como um meio que "vive na excitação de um presente imperioso" (p. 65), a televisão, particularmente através do telejornal, é perspectivada como tendo capacidade de impor "um quadro único da actualidade" (p. 67). Esquenazi prefere não se refugiar no impacte da imagem televisiva, exaltando, antes, "o poder do dispositivo da informação em directo" (p. 67). Não se pense, no entanto, que disso sobressaem grandes euforias em relação ao pequeno ecrã. Pelo contrário. As afirmações de que hoje "as notícias são menos uma fonte de saber do que de emoções" e de que "o telepúblico é mais considerado como um espectador do que um actor da actualidade" aproximam-nos de autores como Karl Popper e Pierre Bourdieu cujas teses apocalípticas em relação ao pequeno ecrã são bem conhecidas (vide Popper, K. et al., La Télévision: Un danger pour la démocracie, Anatolia, Paris, 1994; e Bourdieu, P. , Sur la télévision, Liber, Paris, 1996). Talvez fosse útil reler La Télévision de l'intimité (Ed. Seuil, Paris, 1996) e meditar naquilo que aí escreve a socióloga Dominique Mehl, que Jean-Pierre Esquenazi tão bem conhece: "no lugar de colocar em lados opostos o espectáculo e a reflexão, perguntemos se e como o espectáculo incita a pensar" (p. 181).

Ainda que este livro não faça transparecer entusiasmos em relação ao poder que a televisão possa ter para, de maneiras diversas, nos fazer aceder a um "mundo comum", na parte final do capítulo 2, o autor afirma que "o trabalho mediático não pode contentar-se em só dizer o mundo; é preciso", acrescenta, "interpretá-lo a fim de não tornar a experiência incompreensível e longínqua" (p. 74). É através destes meandros do relato do acontecimento - a distinção entre o esforço de descrever e a intenção de tornar inteligível - que se constrói o capítulo seguinte, onde emerge a ideia de que as peças noticiosas que hoje se propõem às audiências submetem-se menos às diversas opiniões do que à aprovação geral. A tirania das fontes, nomeadamente daquelas que 
reúnem um certo estatuto social, não é um dado novo. Basta, por exemplo, ler o trabalho de Sébastien Rouquette (Vie et mort des débats télévisés: 1958-2000, Col. Médias Recherches, Ed. de Boeck, 2001), que estudou meia década de debates televisivos dos canais franceses, para perceber que nos media não fala quem quer, mas quem conquista a legitimidade necessária para isso. A “revolução das fontes”, para usarmos a expressão do investigador brasileiro Manuel Chaparro, é um vector que deveria ter merecido mais atenção, na medida em que é ao nível da institucionalização daqueles que constroem pólos de noticiabilidade que se percebe grande parte do actual desenho dos discursos mediáticos.

Para além dos factos e das pessoas que integram qualquer informação mediática, há um elemento que condiciona a arquitectura daquilo que se pretende noticiar. Referimo-nos ao "dispositivo" que Esquenazi define como “o arranjo material e simbólico que permite a cada media ordenar e apresentar a actualidade” (p. 109). Pensamos que é a este nível que o autor desenvolve melhor os seus argumentos, tocando aspectos essenciais do discurso mediático, nomeadamente as condutas rituais dos actores que protagonizam os factos e os pactos de comunicação celebrados com quem a eles assiste.

Recuperando-se a sociologia de Goffman, reitera-se a ideia de que "os nossos jogos de linguagem contêm fórmulas adaptadas às situações e às convenções de quadros aos quais estão ligados” (p. 108). Tal como a conversação quotidiana é tributária das circunstâncias sociais que fixam papéis, o mesmo se passa com o discurso mediático cuja construção depende de vários factores, de entre os quais sobressai o dispositivo, ou seja, as condições materiais e simbólicas que organizam o tempo, o espaço e a enunciação - três vectores que se influenciam mutuamente. Mais do que permitir a apresentação de vivências, o suporte - que pode ser encarado, em termos gerais, como a natureza do meio de comunicação ou, talvez mais pertinentemente, como aquilo através do qual se constrói uma cena mediática - constitui-se como um elemento que define, mais do que nenhum outro, posições no interior do campo mediático. Pode ser o que se vê menos, mas é certamente o que conta mais. Ao potenciar determinados "actos rituais" e ao impedir outros, o dispositivo - quer tomado numa acepção mais geral, quer perspectivado a um nível mais concreto - impõe uma certa encenação da realidade, que estabelece determinados pactos com o respectivo público que, para serem eficazes, devem levar os receptores a condutas rituais previstas. É para esta problemática que o capítulo 4 nos convoca, tendo como referência principal a televisão, o meio onde se julga (nem sempre com os melhores argumentos) que a encenação é mais exacerbada.

Embora reconheça que um meio de comunicação social, "ao contrário de um fabricante de automóveis", não tem hoje a possibilidade de propor produtos radicalmente diferentes dos seus congéneres (p. 127), Jean-Pierre Esquenazi faz da definição da identidade discursiva um trabalho obrigatório em cada órgão de comunicação, reservando para a sociologia dos media a tarefa crítica de confrontar o "projecto projectado" com o "projecto realizado" (p. 128). A questão que fixa nas primeiras páginas do capítulo 5 - "como compreender a produção da identidade do discurso a partir do projecto da empresa?"- serve ao autor de guia para se deter nos meandros que a definição de uma identidade oculta. Partindo da premissa de que "toda a insti- 
tuição mediática faz parte do campo social onde se situa" (p. 129), estando por isso submetida às obrigações que aí se fixam, o autor descobre nas necessidades do campo parte da resposta à sua interrogação. A outra situa-se no conjunto de convenções e de normas práticas do trabalho jornalístico que está em permanente interacção com os constrangimentos impostos pelo campo onde se integram (pp. 129-130). Ainda que a identidade garanta um certo agir comunicacional, isso não implica uma total previsibilidade do trabalho jornalístico. "Um media", defende Esquenazi, "deve habituar o público à sua identidade discursiva, mas não deve deixar os seus hábitos ou estereótipos ditar uma lei muito previsível” (p. 132). Essa é, aliás, uma das regras básicas da engenharia da programação que o livro não explora, embora seja a manifestação identitária mais visível do pequeno ecrã.

Apesar de, nas páginas iniciais deste livro, Jean Pierre Esquenazi ter afirmado não enveredar por uma abordagem que colocasse no seu centro a análise dos media enquanto estruturantes do espaço democrático (p. 8), na recta final reconhece que a identidade dos media, a par de ter um papel a montante (no plano da produção), tem uma importância maior a jusante (no plano da recepção), na medida em que permite apreender a noção daquilo que constitui o público de um meio de comunicação social (p. 151). Mais do que saber quem vê uma emissão, quem lê um jornal ou quem acompanha um programa de rádio, seria pertinente explorar os contornos que esses produtos mediáticos traçam de um espaço público a partir do qual são estruturados, mas em relação ao qual também se assumem como estruturantes. Para a compreensão dessa dualidade, a análise dos media enquanto discursos - tributários de uma lógica própria, mas também influenciados por elementos exteriores - é certamente um caminho que iluminará com outras cores o respectivo campo. Mais do que evidenciar este ou aquele aspecto, talvez seja este o ensinamento maior desta obra. 